International Journal of Engineering \& Technology, $7(2.14)(2018) 171-176$
International Journal of Engineering \& Technology
Website: www.sciencepubco.com/index.php/IJET
Research Paper

\title{
Crack identification using piezoelectric testing on carbon steel pipe for transverse, longitudinal and hole defects with low excitation frequency
}

\author{
Ahmed N. Abdalla ${ }^{1}$, Kharudin Ali ${ }^{2,3 *}$, Johnny Koh Siaw Paw ${ }^{2}$, Chong Kok Hen ${ }^{2}$, Tan Jian Ding, \\ M. Sham Maizal ${ }^{3}$, M. Izzat $^{3}$ \\ ${ }^{1}$ Faculty of Electronic Information Engineering, Huaiyin Institute of Technology, Huai'an Jiangsu, China \\ ${ }^{2}$ Institute of Sustainable Energy (ISE), UNITEN, 43000 Selangor, Malaysia \\ ${ }^{3}$ Faculty of Electrical and Automation Engineering Technology, TATIUC, 24000 Terengganu, Malaysia \\ *Corresponding author E-mail: kharudin@tatiuc.edu.my
}

\begin{abstract}
AC excitation signal is most widely used in Non Destructed Testing (NDT) devices for Piezoelectric Technique (PZT) method in an inspection. This paper is presenting the application of piezoelectric with end to end method for defect identification for Carbon Steel Pipe (CSP) where the frequency is used around $1 \mathrm{kHz}$ until $6 \mathrm{kHz}$ for standard pipe, transverse defect pipe, longitudinal defect pipe and hole defect pipe. From here, the identification of defect signal by based on the signal pick value and different pick signal between ordinary pipe (without defect) and defects pipe are analysis. The result shows that the standard pipe will give the high amplitude of signal compare the defect pipe by based on the type of defect, size of defect and depth of defect. Findings from the comparative study, validate the application of piezoelectric show that the different amplitude of the signal is directly proportional with excitation signal frequency and through the experiment, the longitudinal defect is contributed the different high signal until $79.7 \%$ compared to the hole and transverse defect $74.4 \%$.
\end{abstract}

Keywords: Piezoelectric; Non-Destructed Testing; Defect; Amplitude; Ac Excitation.

\section{Introduction}

NDT widely used in industry for inspection without any causing of physical damage on material testing [1-2]. Material defects and corrosion are dynamic processes due to various factors including time and process variable [3-4]. Non-destructive testing methods are the latest trends today based on the propagation of sonic and ultrasonic waves and widely used in engineering material testing [5-6]. Various agencies have extended the use of NDT techniques including highway agencies using ultrasonic testing to determine the thickness of the asphalt on the road without deterioration [7]. The ultimate source for ultrasonic is the piezoceramic disc, which is an active element for transmitter and receiver transducer $[5,8]$. Inspection methods and effectively is very important, especially to strengthen the reliability of the age structure and increase safety. Various methods can be seen through scientific literature as an example through ultrasonic C-scan [9] and infrared temperature measurements [10]. Based on the latest study on the more effective measurement techniques against the damage assessment of the structure is based on Lamb wave visualization technique [11-12]. Several methods have been proposed to enhance the effectiveness of measurement based on the interpretation of the wave signal in the process, especially for the damage measuring on the material structure through visualization techniques for Lamb wave signals measured by the sensor [13-14]. Internal changes resulting in a attenuations through the fault detection (DI) method can be overcome by the attenuation index (AI) [15-16] method as a diagnostic pathway and it is used as a comparison of the depletion signal to the baseline signal. Five approaches have been classified into the DI method: (1) The spectral finite element analysis method [17], (2) the arrival / arrival information of the TOA / TOF from the wave reflection / dissemination [18], (3) wavelet, as reported by [19], (4) statistical analysis methods [20-21] and (5) frequency-time analysis [22]. Through the use of an acoustic -ultrasonic / piezoelectric method conducted by the research and the interpretation of the change of the current wave need to be studied in depth as one of the methodologies. It is proposed to identify the waveform of Lamb that is excitedly excited from the actuator.

In this paper, the system development consists of designing the piezoelectric transducer arrays, with the low frequency generating for piezoelectric, processing and acquisition and comparison between the standard pipe and defect pipe testing. In the system, the on-line waveform monitoring on the different defect is developed by using piezoelectric transducer for inspection. The executions of the scheme are analyzed in a MATLAB based piezoelectric interfacing for experiments (MBP). In the coming section, an MBP scheme is discovered, including the array scheme, data acquisition, MBP data comparing and data processing technique.

\section{Related work}

\subsection{Principal component analysis (PCA)}

The difficulty in finding similarities to the information obtained is the primary challenge in analyzing data. In other words, diversity 
of analytical methods is made to solve the problem and at the same time solves the problem of explaining vast quantities of information. In 1901, Pearson at the first time has described the analysis of components as a multivariate analysis tool and subsequently adopted by Hotelling in 1933 [23]. Based on the method, only relevant data and information being applied for the variation of changes to the measured variables. In obtaining and analyzing these variables, data transformation is based on current coordinate values against new coordinates for data re-expression other than filtering, eliminating noise and avoiding redundancy. This redundancy is measured based on the correlation between the variables [24]

The principle of component analysis can be divided into two mechanisms: (i) Based on correlation; (ii) Covariance. Both of these mechanisms are very important for PCA to be scalable and they need to be normalized. Various methods can be used for the normalization of data [24-25]. Based on the diversity of applications used, PCA is one of the instruments that can reduce data dimensions. Toolbox diversity is used to analyze data for PCA [26]. Due to the perfection of PCA modeling, the data is compiled in matrix form.

\subsection{PCA modelling}

The construction of the PCA model can be carried out in several measurements: (i) Through a healthy structure; (ii) Variables or sensors based on time-shifting (L-1) where $\Delta$ time in sampling; and (iii) ( $\in \mathrm{CN}$ ) or experimental trials. All of the following steps can be discredited into matrix form as follows:

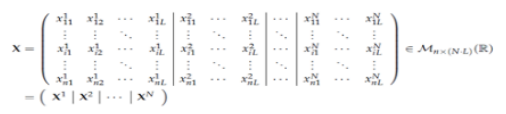

\subsection{Projection of new data onto the PCA model}

The actual construction to scrutinize is charged along as is the signal as the one that cost the healthy one in section 2.1.1. Consequently, while the measurements are received from $(\mathrm{NCN})$ detectors during (L-1) $\Delta$ seconds and (vEN) experimental tests, a new data matrix $\mathrm{Y}$ is built as in (2):

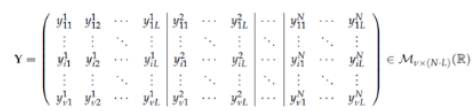

They are deserving noting. At this point, that the natural number $\mathrm{n}$ (the number of rows of matrix $\mathrm{Y}$ ) isn't inevitably capable $\mathrm{n}$ (the number of rows of X). Merely the number of columns of $Y$ essential accord in addition to that by $\mathrm{X}$; that's, in both cases. The number $\mathrm{N}$ of detectors and the number of time instants $\mathrm{L}$ must be matched. The matrix has to be scaled to define a new matrix $\hat{Y}$ as in (3):

$y_{i j}^{k}:=\frac{y_{i j}^{k}}{o^{k}}, \frac{\mu_{j}^{k}}{o^{k}}, i=1, \ldots, L, k=1, \ldots, N$,

where $u_{j}^{k}$ and $\sigma^{k}$ is real numbers are computed and defined $r^{i}=\breve{Y}(i,:) \in R^{N \cdot L}, i=1, \ldots, v$ is a projection of each row vector and $\hat{Y}$ space spanned by the eigenvectors in $\hat{P}$ [26].

$t^{i}=r^{i} \cdot \hat{P} \in R^{l}$

For each row vector $r^{i}, i=1, \ldots, v$, the first component of vector ti is called the first score or Score 1; similarly, the second component of vector $t^{i}$ is called the second score or Score 2. Once the actuator initiates the propagation of the signal in the pipe, only the reflected signal will be returned to the sensor. Figure 1 shows the distribution of the signal in a damaged pipe. Whereas, Figure 2 shows the propagation of the signal in free damage pipe.

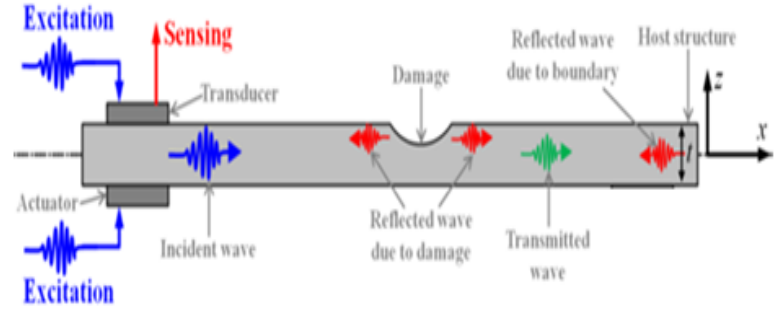

Fig. 1: Illustration of the Signal Propagation through a Damaged Pipe.

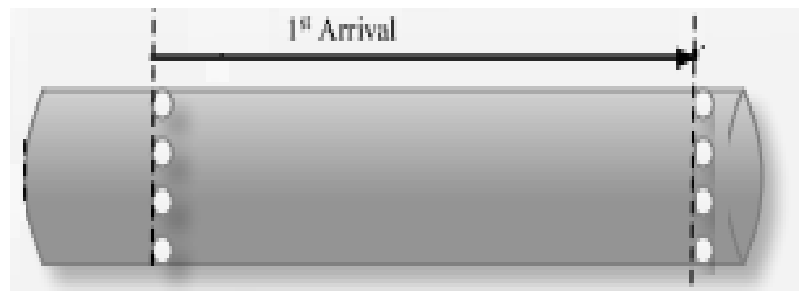

Fig. 2: The Propagation of the Signal in Free Damage Pipe.

Dependency on the high frequency or relative speed will cause the signal to be transmitted quickly to the receiver. If otherwise, the signal receiver will be slow. This signal transmission is performed continuously to see the amplitude changes of the test pipe to assess the extent of the damage to the pipe. Also, the original form of the signal will change the pattern and shape when it comes to pipes with no breaks or taps with damage. Based on this data, the amplitude ratio and the signal form to the no-break pipe and broken pipe are made for analysis purposes.

\section{Proposed method}

The proposed PZT technique as shown in Figure 3 is divided into two parts namely simulation by using MATLAB Simulink with including the fuzzy logic rules and seconds hardware interfacing between piezoelectric sensor and controller. The purpose of simulating in the experiment is to validate the results of hardware interfacing experiment and providing a comparative study. The following subsections explain each component of design and implementation the proposed PZT technique implementation.

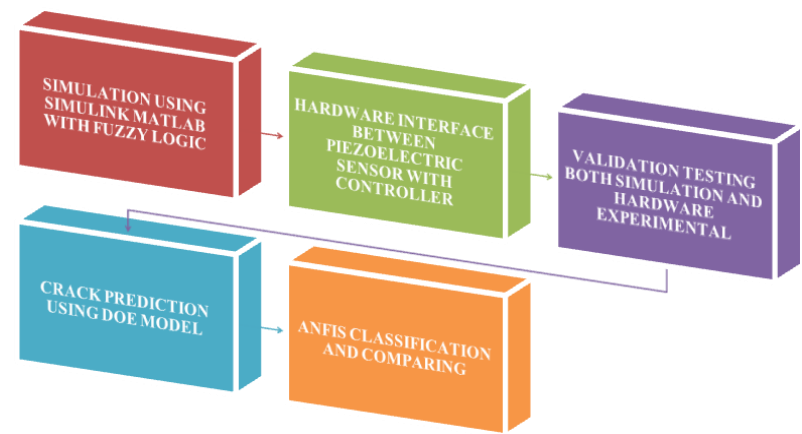

Fig. 3: Block Diagram for PZT Technique Process.

\subsection{Fuzzy system}

In evaluating and comparing real data to PZT, the simulation process is used. This is presumably intended for a signal to be obtained by the AC input given. Therefore, MATLAB / Simulink are used as a platform for the simulation. Based on Figure 4, for the simulation of PTP, there are four main parts made for the application of fuzzy logic in the system. The main part is the feedback or input for PZT, in turn, is part of the conditioning, the third or the most important is the process of fuzzy logic and lastly is output or the feedback obtained through the four sections. 


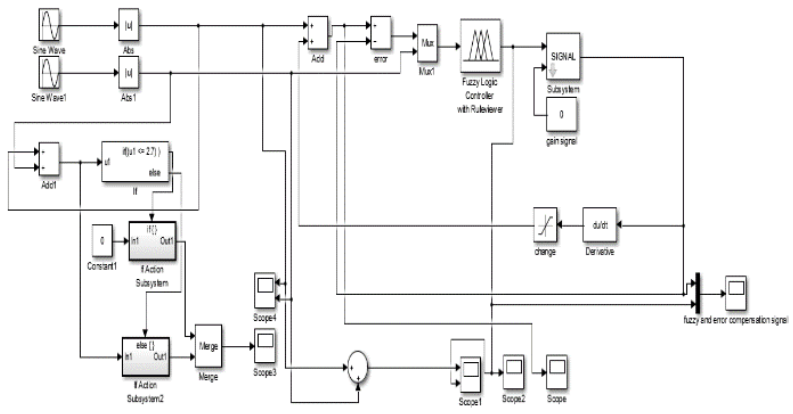

Fig. 4: Simulink for PTP Simulation.

\subsection{Proposed PTP technique using fuzzy logic}

Fuzzy logic is an important part of analyzing any data that is included based on the rules setting besides the waveform of the Fuzzy Inference System (FIS) set for the analyst against: phase, amplitude and width. The scheme used as a fuzzy determination consists of system output, system input fuzzy rules i.e. IF-THEN and membership function (MF). The input for this fuzzy is the crack signals that being measured on test material based on loop width, amplitude and phase. Schema output is the actual crack data based on the width of the defect, the depth and shape of the material defect. The MF or member in the membership is functioning as a reaction for every fuzzy set based on a scale of 0 to 1 . The accuracy of the fuzzification is important for any fuzzy design created based on MF. IF-Than is a fuzzy rule that is declared as a form or language condemnation to illustrate the relative between input and output as example: IF the amplitude (input) is low THEN the crack depth is shallow (output). Fuzzy rules have been applied in this system to enable fuzzy logic to function other than execution or lingual. Finally, defuzzification is needed to alter the lingual variables to the intricate values of mathematics. Figure 5 shows the whole system of fuzzy logic built based on input and rules set.

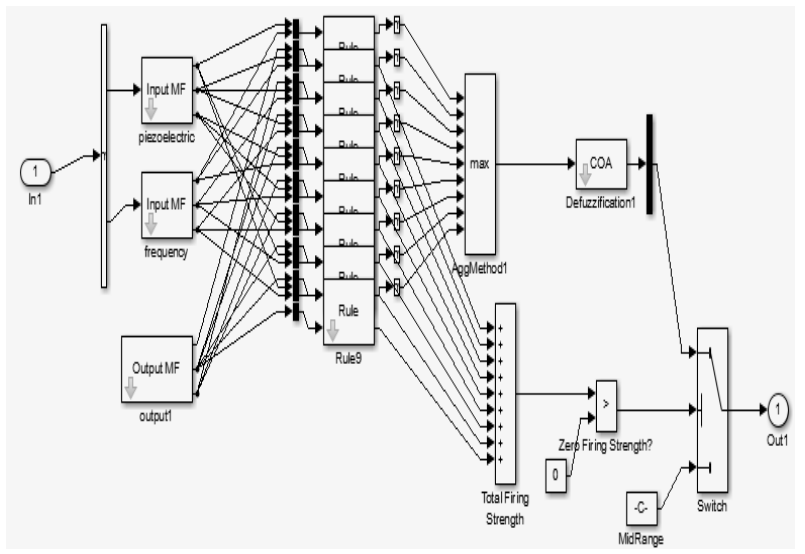

Fig. 5: Internal Block Function in Fuzzy Logic.

\subsection{Rules of fuzzy logic}

To complete the fuzzy logic block setting, the rule of the fuzzy block is set according to rule editor for frequency and depth measuring block. Figure 6 shows the fuzzy rules that have nine rule has been set.

\footnotetext{
1. If (piezoelectric is lowdefect) and (frequency is lowfrequency) then (output1 is normaldefect) (1) 2. If (piezoelectric is depthdefect) and (frequency is lowfrequency) then (output1 is dangerdefect) (1) 3. If (piezoelectric is depthdefect) and (frequency is mediumfrequency) then (output1 is baddefect) (1) 4. If (piezoelectric is depthdefect) and (frequency is highfrequency) then (output1 is baddefect) (1) 5. If (piezoelectric is dengerdefect) and (frequency is lowfrequency) then (output1 is dangerdefect) (1) 6. If (piezoelectric is dengerdefect) and (frequency is mediumfrequency) then (outputt is dangerdefect) (1) 7. If (piezoelectric is dengerdefect) and (frequency is highfrequency) then (output1 is baddefect) (1) 8. If (piezoelectric is lowdefect) and (frequency is mediumfrequency) then (outputt is baddefect) (1) 9. If (piezoelectric is lowdefect) and (frequency is highfrequency) then (outputt is baddefect) (1)
}

Fig. 6: Fuzzy Rules.

\section{Experimental setup}

The general diagram of the proposed PZT techniques with end to end method is shown in Figure 7. Figure 7(a) illustrates the Schematic diagrams of the experiment setup, whereas Figure 7(b) shows the photo of experiment setup. The PZTs that used actuators amount in the appropriate locations as shown in Figure 7. An active axis of each piezoelectric is parallel to the axis of the pipe. The eight pieces of PZT are arranged with the equal distance on the surface of the pipe and located at the end of the pipe along the circumferential direction. The eight PZT disc are connected in parallel, so that the same input signal voltage applied to each PZT disc in the simultaneously ring.

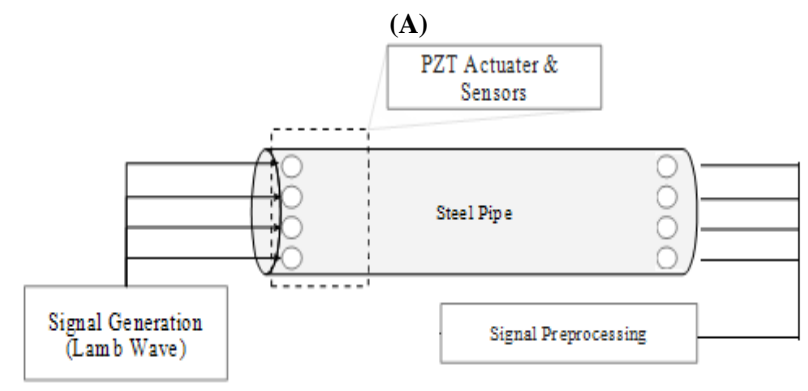

(B)

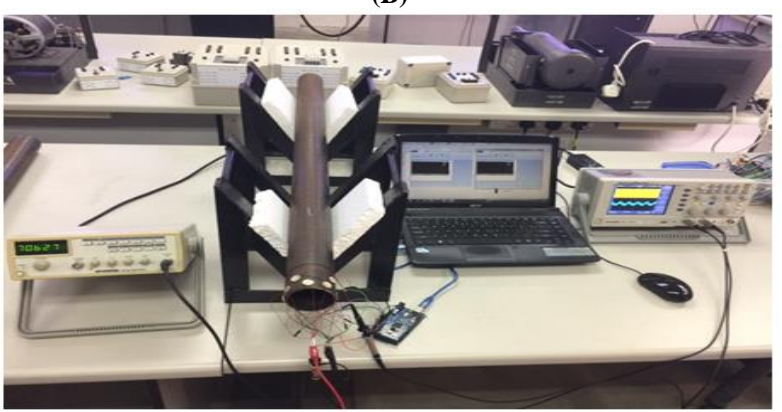

Fig. 7: Diagram of PZT System (A) Schematic Diagrams of the Experiment Setup, (B) Photo of the Experiment Setup.

The sample and tools that are required for achieving the research objectives are described in Table 1 where it describes all tools that needed in the experiment such as pipe sample, sensors, cables and supporters.

Table 1: Tool Used In Experimental

\begin{tabular}{|c|c|c|c|}
\hline No. & Item & Description & $\begin{array}{l}\text { Quan- } \\
\text { tity }\end{array}$ \\
\hline 1 & Pipe & $\begin{array}{l}\text { Steel Pipe L } 1015 \mathrm{~mm}, \mathrm{D} 60 \mathrm{~mm}, \mathrm{~T} \\
4 \mathrm{~mm} \\
\text { Piezoelectric Transducer }\end{array}$ & 15 \\
\hline 2 & PZTs & $\begin{array}{l}8 \text { as Actuators } \\
4 \text { as Sensors }\end{array}$ & 12 \\
\hline 3 & $\begin{array}{l}\text { Data acquisi- } \\
\text { tion }\end{array}$ & Oscilloscope & 1 \\
\hline 4 & $\begin{array}{l}\text { Signal genera- } \\
\text { tor }\end{array}$ & Wave Generator & 1 \\
\hline 5 & Cables & Cables for connecting & 3 \\
\hline 6 & Stands & $\begin{array}{l}V \text { shape stands for holding the } \\
\text { pipe }\end{array}$ & 2 \\
\hline 7 & Isolator & Polystyrene & 4 \\
\hline 8 & Epoxy & & 1 \\
\hline 9 & Controller & & 1 \\
\hline
\end{tabular}

There are twelve PZT discs with dimensions of $12.7 \mathrm{~mm}$ diameter and $2.0 \mathrm{~mm}$ thickness was used, eight PZTs as actuators and four PZTs as sensors. Figure 8 illustrates the geometry of the PZT. The commercial cyanoacrylate adhesive is used to bond the PZT to the surface of the specimen. 


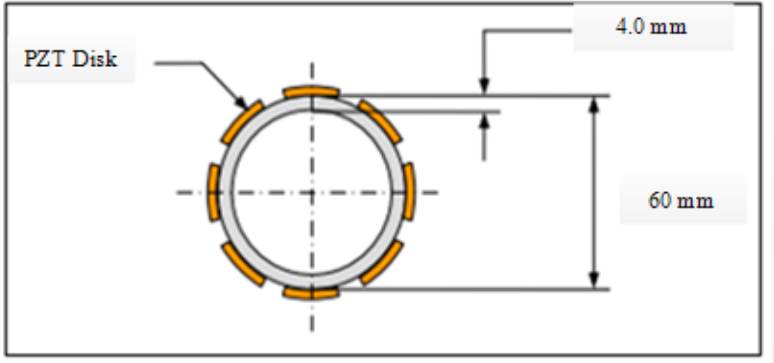

Fig. 8: A Cross Section for the Distribution of the PZTS.

The experiments for Lamb waves consist of AC draw in one location on the pipe. This method is called as AC excitation. In AC excitation method, the PZTs have the same AC voltage input signal in each PZT in the ring arrangement with simultaneously. The actuators are connected to the signal generator. Also, the PZTs that served as the sensors wired together in parallel in the second ring. These PZTs are connected to the oscilloscope. PZTs are used as sensors located at two locations along the axial length of the pipe as shown the Figure 9. The first location at the $2 \mathrm{~mm}$ start on the left of pipe, and the second at $15 \mathrm{~mm}$ from the first axial of the pipe.

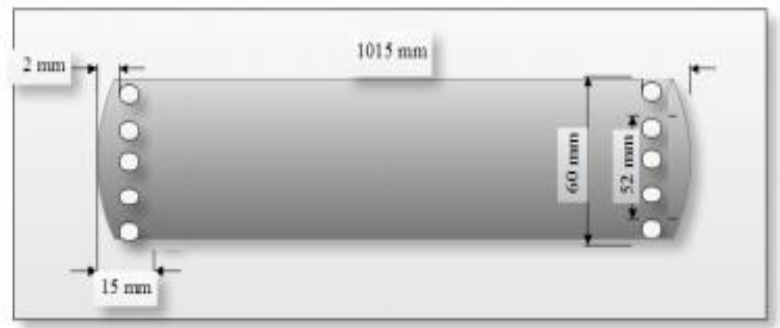

Fig. 9: Illustrated PZT Actuator/Sensor Position.

\section{Result and discussion}

All the result is displayed by the signal pick value based on the value of the frequency that was set up. The signal will be seen to identify the crack in the carbon steel pipe. The signal including the abnormal if the crack detected on the carbon steel pipe and will be displayed on the Simulink scope. Frequency is used from function generator are being set from $1 \mathrm{kHz}$ until $6 \mathrm{kHz}$ for the transmit piezoelectric element. The result will be collected based on the signal pick in the scope within all the sample of the carbon steel pipe that was used to compare the signal pick for the normal specimen that not have the defect and the specimen that have the defect. The sample result is shown in Figure 10 within taken from the different defect but same frequency. Figure 10(a) Normal pipe signal without defect, Figure 10(b) for longitudinal defect signal, Figure 10(c) hole defect signal and Figure 10(d) transverse/ vertical defect signal will be shown in the signal form. The signal pick value will be converting to the voltage value that has the formula to calculate it. The method to calculate voltage value is

(Pick Value/1023) x 5V

\subsection{Testing sample}

The result is for the normal pipe of the carbon steel that will be compared with the sample of the carbon steel pipe that has the longitudinal defect, hole defect and transverse defect. Figure 10 shows the sample pipe defect by using $1 \mathrm{kHz}$ frequency for excitation signal for the actuator. Table 2 for general pipes is used as a reference for every implementation of pipes in industries such as petroleum and natural gas industries. The tables are details about dimensions for pipe including thickness and diameter of the pipe. The physical characteristics of the pipe used are shown in Table 2.

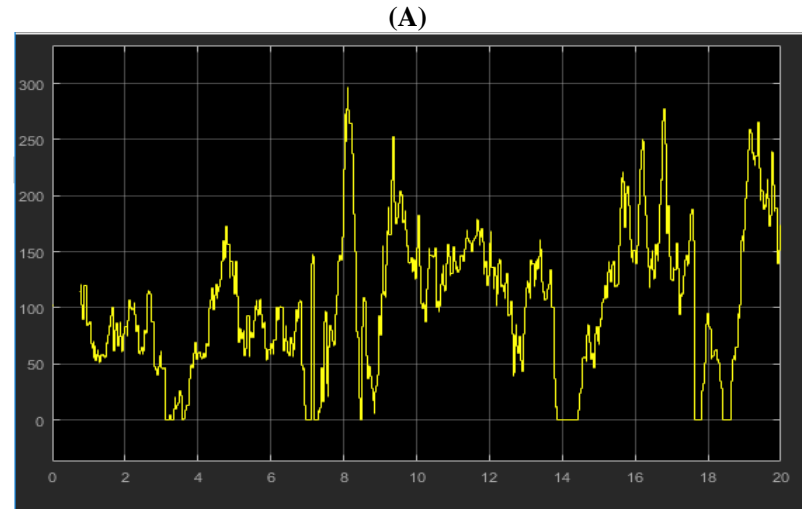

(B)

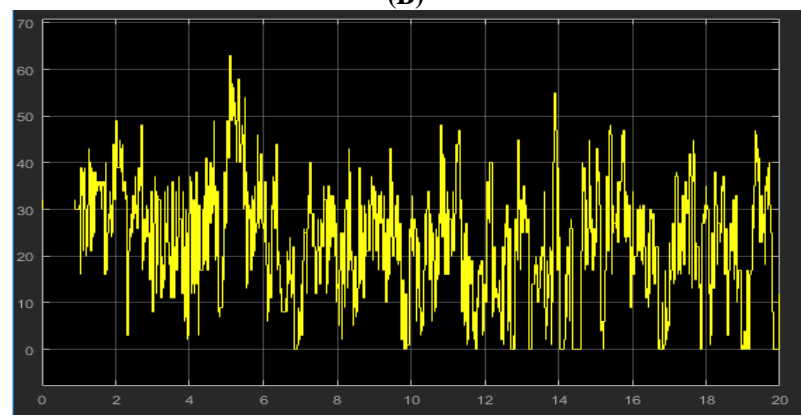

(C)

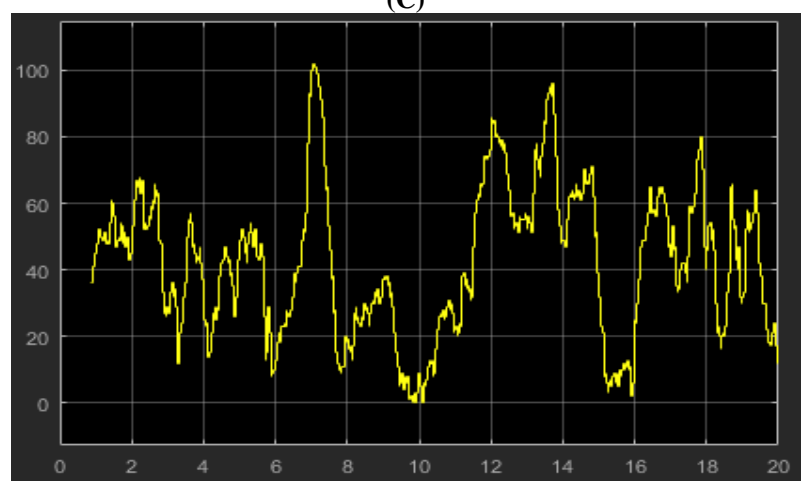

(D)

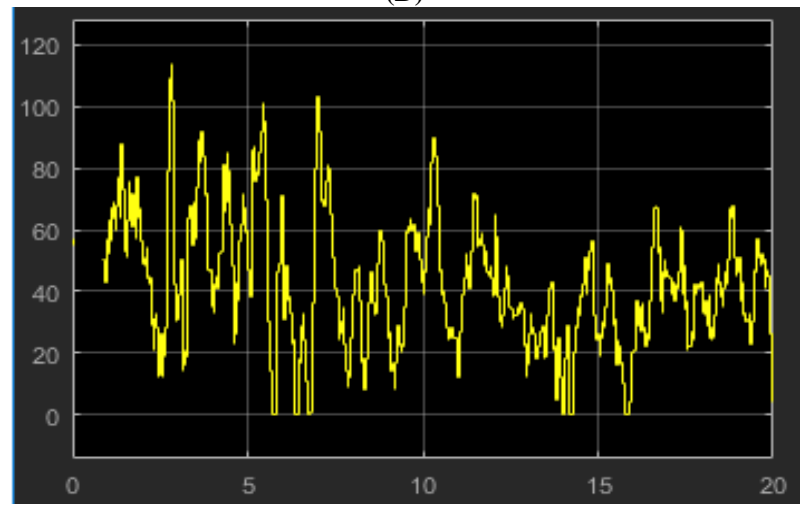

Fig. 10: Sample of Signal According (A) Normal Pipe, (B) Longitudinal Defect Pipe, (C) Hole Defect Pipe, (D) Transverse Defect Pipe.

Table 2: The Specification of Steel Pipe Parameters

\begin{tabular}{llllll}
\hline $\begin{array}{l}\text { Modulus } \\
\text { Elasticity, } \\
\text { GPA }\end{array}$ & $\begin{array}{l}\text { Poisson } \\
\text { Ratio }\end{array}$ & $\begin{array}{l}\text { Density, } \\
\rho \mathrm{kg} / \mathrm{m}^{3}\end{array}$ & $\begin{array}{l}\text { Length, } \\
\mathrm{mm}\end{array}$ & $\begin{array}{l}\text { Wide, } \\
\mathrm{mm}\end{array}$ & $\begin{array}{l}\text { Thick, } \\
\mathrm{mm}\end{array}$ \\
\hline 210 & 0.32 & 7850 & 1000 & 60 & 4 \\
\hline
\end{tabular}

\subsection{Result for carbon steel defect}

Figure 11 shows the defect designing on carbon steel pipe for three defect within Figure 11(a) longitudinal defect, Figure 11(b) hole defect and Figure 11(c) transverse defect. Based on the result at 
Figure 11(a), the testing shows the signal pick value for the normal frequency is 300 and the signal pick value for the longitudinal defect pipe is 63. From that result, the signal percentage comparison for the normal and defect signal is $91 \%$ decreased from normal signal pick value. The voltage for normal pick value is $1.46 \mathrm{~V}$ and the voltage value for longitudinal defect pick value is $0.30 \mathrm{~V}$. The compare for voltage value is $1.16 \mathrm{~V}$. On the result from Figure 11(b), the testing shows the pick value for the normal frequency is 300 and the pick value for the hole defect pipe is 100 . From that result, the signal percentage comparison for the normal and defect signal is $67 \%$ decrease. The voltage for the normal pick value is $1.46 \mathrm{~V}$ and the pick value voltage for defect pipe is $0.48 \mathrm{~V}$. The comparison of voltage is $0.98 \mathrm{~V}$. Lastly, the result at Figure 11(c) shows the pick value for the normal frequency is 300 and the pick value for the defect pipe is 100 . From that result, the signal percentage comparison for the normal and defect signal is $67 \%$ decrease. The voltage for the normal pick value is $1.46 \mathrm{~V}$ and the pick value voltage for defect pipe is $0.48 \mathrm{~V}$. The comparison of voltage is $0.98 \mathrm{~V}$.

(A)

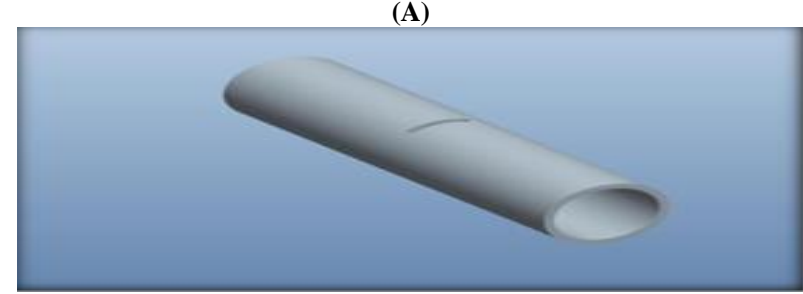

(B)

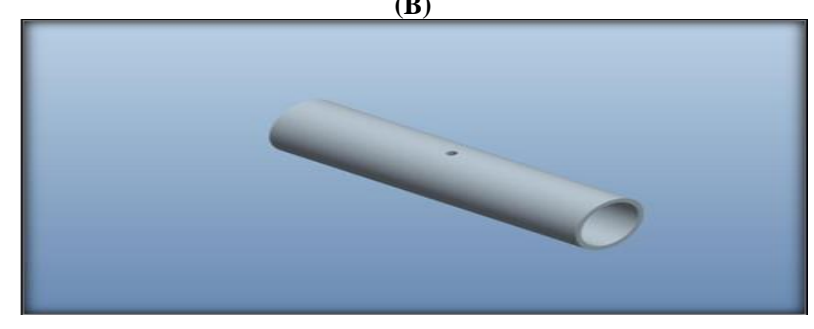

(C)

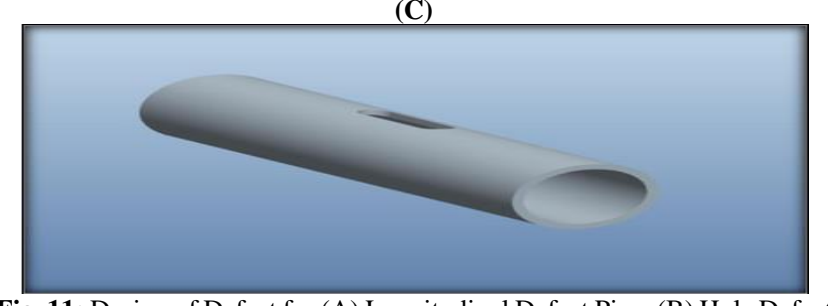

Fig. 11: Design of Defect for (A) Longitudinal Defect Pipe, (B) Hole Defect and (C) Transverse Defect

\subsubsection{Defect measurement}

Table 3 shows the frequency that used for pick value of signal between the normal pipe and defect pipes including longitudinal, hole and vertical defect. The comparison between the normal pipe and defect pipe are shown in the Table 4. It shows the effect of frequency $(1 \mathrm{khz}-6 \mathrm{khz})$ at actuator against the piezoelectric sensor measuring between normal pipe and hole defect pipe. The value of the signal for normal and defect pipe also for the calculation for comparing between normal and defect pipe for carbon steel pipe. Figure 4 shows the different value of the normal pipe and defect pipe by base on frequency. Vertical / Transverse defect calculation Table 3 shows the frequency that used the pick value of the signal for normal pipe and transverse defect also the calculation of comparison between normal and defect pipe. The different between this two are shown in Figure 14.
Table 3: The Frequency and Pick Value of Signal

\begin{tabular}{lllll}
\multicolumn{5}{c}{ Table 3: The Frequency and Pick Value of Signal } \\
\hline $\begin{array}{l}\text { Frequency } \\
(\mathrm{kHz})\end{array}$ & $\begin{array}{l}\text { Normal } \\
\text { Amplitude } \\
(\mathrm{pp})\end{array}$ & $\begin{array}{l}\text { Vertical } \\
\text { Amplitude } \\
(\mathrm{pp})\end{array}$ & $\begin{array}{l}\text { Hole Am- } \\
\text { plitude } \\
(\mathrm{pp})\end{array}$ & $\begin{array}{l}\text { Longitudinal } \\
\text { Amplitude } \\
(\mathrm{pp})\end{array}$ \\
\hline 1 & 300 & 100 & 100 & 63 \\
2 & 350 & 116 & 116 & 116 \\
3 & 570 & 118 & 118 & 120 \\
4 & 620 & 170 & 165 & 140 \\
5 & 630 & 178 & 178 & 150 \\
6 & 880 & 225 & 225 & 178 \\
1 & 300 & 97 & 93 & 55 \\
2 & 350 & 104 & 105 & 106 \\
3 & 570 & 108 & 103 & 117 \\
4 & 620 & 150 & 148 & 134 \\
5 & 630 & 145 & 178 & 137 \\
6 & 880 & 200 & 200 & 170 \\
1 & 300 & 89 & 86 & 50 \\
\hline
\end{tabular}

\subsection{RSM result}

Table 4 show the ANOVA response surface for Longitudinal defect in reduction quadratic model where including the source, sum of square, df, mean square F value, p-value (Prob > F) and significant data. From here, the significant data should be less than 0.05 for Prob $>$ F.

Table 4: ANOVA Longitudinal Analysis of Variance Table for Response Surface Quadratic Model

\begin{tabular}{lllllll} 
Source & $\begin{array}{l}\text { Sum of } \\
\text { Squares }\end{array}$ & $\begin{array}{l}\text { d } \\
\text { f }\end{array}$ & $\begin{array}{l}\text { Mean } \\
\text { Square }\end{array}$ & F & $\begin{array}{l}\text { p-Value } \\
\text { Prob }>\text { F }\end{array}$ & \\
\hline Model & 19924.69 & 5 & $\begin{array}{l}3984.93 \\
8\end{array}$ & $\begin{array}{l}101.4 \\
348\end{array}$ & $<0.0001$ & $\begin{array}{l}\text { signifi- } \\
\text { cant }\end{array}$ \\
$\begin{array}{l}\text { A-Fre- } \\
\text { quency }\end{array}$ & 86.4967 & 1 & 86.4967 & $\begin{array}{l}2.201 \\
734\end{array}$ & 0.1814 & \\
B-Nor- & 27.00663 & 1 & 27.0066 & 0.687 & 0.4344 & \\
mal & & & 3 & 441 & & \\
AB & 45.54554 & 1 & 45.5455 & 1.159 & 0.3173 & \\
& & & 4 & 341 & & \\
A^2 & 0.001722 & 1 & 2.00172 & 4.38 & 0.9949 & \\
B^2 & 115.5087 & 1 & 115.508 & 2.940 & 0.1301 & \\
Pure & 275 & 7 & 39.2857 & & & \\
Error & & 1 & & & \\
Cor To- & 20199.69 & 1 & & & & \\
tal & & 2 & & & & \\
\hline
\end{tabular}

Inal equation in terms of coded factors:

Longitudinal $=+129.10+37.65 * \mathrm{~A}+21.35 * \mathrm{~B}-168.12 * \mathrm{~A} * \mathrm{~B}-0.46 * \mathrm{~A}^{2}$ $+154.48 * \mathrm{~B}^{2}$

Final equation in terms of actual factors:

Longitudinal $=+192.59623+152.39073 *$ Frequency $-1.28220 *$ Normal-0.23189*Frequency*Normal-0.073418*Fre-

quency $^{2}+1.83682 \mathrm{E}-003 *$ Normal $^{2}$

From Figure 12 show the internally studentized residuals for longitudinal defect, where the 2 point in higher residuals (170-179) at the -0.85 and 0.90 . The rest of the points are lower than 170 and more than 50 by follow the color bar.

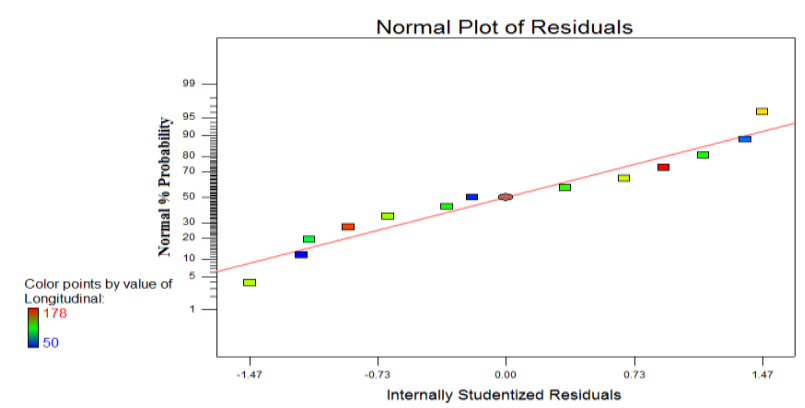

Fig. 12: The Normal Plot of Residuals Graph. 
Figure 13 show the effect of frequency and normal pipe at longitudinal defect. From here, the higher measurement (red color) will be show when the frequency $3.50 \mathrm{kHz}$ until $6.00 \mathrm{kHz}$ where the amplitude of longitudinal are from 250 until 470 peak and the lower amplitude (blue color) at frequency $1.00 \mathrm{kHZ}$ until $2.25 \mathrm{kHz}$ within amplitude on 0 to 30 peak. From here, the good frequency on longitudinal defect identification are in $6 \mathrm{kHZ}$ where giving the maximum signal defect.

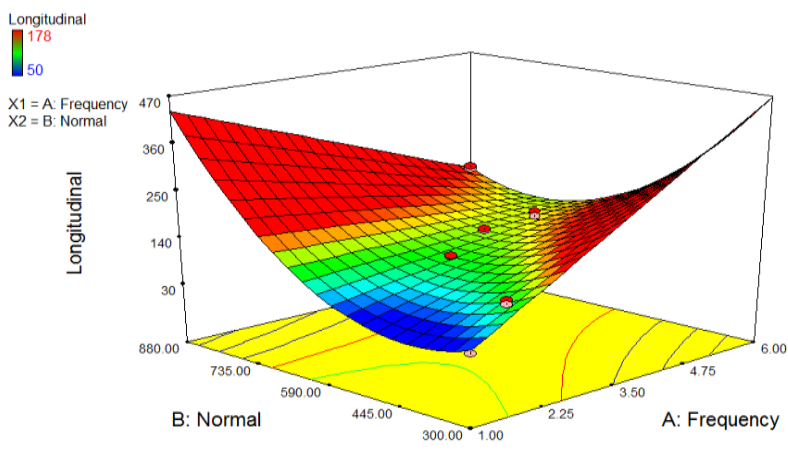

Fig. 13: 3D Graph for Effect on Frequency and Comparing with Normal Pipe and Longitudinal Defect Pipe.

\section{Conclusion}

The piezoelectric element is one of the ways to make the inspection easier. Such the inspection on pipe only needs to place the piezoelectric element at one place after that can see the result in the MATLAB software that already installs on the laptop. For here, the piezoelectric element has been purpose by focusing inspection at the carbon steel pipe. In here, the different signal form and pick value got from the result after doing the inspection. The frequency that was used is $1 \mathrm{kHz}, 2 \mathrm{kHz}, 3 \mathrm{kHz}, 4 \mathrm{kHz}, 5 \mathrm{kHz}$ and $6 \mathrm{kHz}$. From the carbon steel pipe $6 \mathrm{~mm}$ thickness, the conclusion from the result are the defect signal pick value will be lower than the normal signal pick value. For the comparison, materials are the PVC pipe also being inspected using the piezoelectric element. The same frequency also is used $1 \mathrm{kHz}, 2 \mathrm{kHz}, 3 \mathrm{kHz}, 4 \mathrm{kHz}, 5 \mathrm{kHz}$ and $6 \mathrm{kHz}$ from that the conclusion is the piezoelectric element also can be used to inspect the composite materials such as PVC pipe. The signal for normal and defect is different and can be used to compare with the carbon steel pipe. From the experiment, the signal pick value from all defects was observed. The normal pick value compared with defect pick value. Then, the form the pick value can give the voltage value. From the pick value, the lowest pick value that gets is from the longitudinal defect. The maximum pick value of longitudinal deficiency is for carbon steel $6 \mathrm{~mm}$ is 178 and for PVC is 375 .

\section{Acknowledgement}

The authors would like to express gratitude to Faculty of Electronic Information Engineering, Huaiyin Institute of Technology for expertise support and UNITEN for the sponsor of this research under the BOLD of scholarship scheme and also under the BOLD funding scheme for Postdoctoral Engineering UNITEN. Not forget gratitude to TATIUC (FTKEA) for facility and equipment for experimental under the STG (9001-1806).

\section{References}

[1] Ali KB, Abdalla AN, Rifai D \& Faraj MA (2017), Review on system development in Eddy current testing and technique for defect classification and characterization. IET Circuits, Devices and Systems 11, 330-343.

[2] Paw JK, Ali K, Hen CK, Abdallah AN, Ding TJ, Ahlam NA \& Eirfan N (2018), Encircling probe with multi-excitation frequency signal for depth crack defect in eddy current testing. Journal of Fundamental and Applied Sciences 10,949-964.

[3] Rao J, Ratassepp M, Lisevych D, Hamzah Caffoor M \& Fan Z (2017), On-line corrosion monitoring of plate structures based on guided wave tomography using piezoelectric sensors. Sensors 17, 1-14.

[4] Rifai D, Abdalla AN, Ali K \& Razali R (2016), Giant magnetoresistance sensors: A review on structures and non-destructive eddy current testing applications. Sensors 16, 1-30.

[5] Prassianakis IN \& Prassianakis NI (2004), Ultrasonic testing of nonmetallic materials: Concrete and marble. Theoretical and Applied Fracture Mechanics 42, 191-198.

[6] Chen L, He F \& Sammut K (2007), Active vibration clamping absorber design. Proceedings of the 14th International Congress on Sound and Vibration

[7] Faraj MA, Abdalla AN, Samsuri FB, Rifai D \& Ali K (2017), Investigate of the effect of width defect on eddy current testing signals under different materials. Indian Journal of Science and Technology $10,1-5$.

[8] Elwalwal HM, Mahzan SB \& Abdalla AN (2017), Crack inspection using guided waves $(\mathrm{GWs}) /$ structural health monitoring (SHM) Journal of Applied Sciences 17, 415-428.

[9] Drinkwater BW \& Wilcox PD (2006), Ultrasonic arrays for non-destructive evaluation: A review. NDT and E International 39, 525541.

[10] Mian A, Han X, Islam S \& Newaz G (2004), Fatigue damage detection in graphite/epoxy composites using sonic infrared imaging technique. Composites Science and Technology 64, 657-666.

[11] Liu Y, Hu N, Xu H, Yuan W, Yan C, Li Y, Goda R, Qiu J, Ning H \& Wu L (2014), Damage evaluation based on a wave energy flow map using multiple PZT sensors. Sensors 14, 1902-1917.

[12] Liu Y, Goda R, Samata K, Kanda A, Hu N, Zhang J, Ning H \& Wu L (2014), An efficient algorithm embedded in an ultrasonic visualization technique for damage inspection using the $\mathrm{AE}$ sensor excitation method. Sensors 14, 20439-20450.

[13] Si L, Wang Q. Rapid multi-damage identification for health monitoring of laminated composites using piezoelectric wafer sensor arrays. Sensors $16,1-12$.

[14] Rifai D, Abdalla AN, Khamsah N, Aizat M \& Fadzli M (2016), Subsurface defects evaluation using eddy current testing. Indian Journal of Science and Technology 9, 1-7.

[15] Faraj MA, Samsuri F, Abdalla AN, Rifai D \& Ali K (2017), Adaptive neuro-fuzzy inference system model based on the width and depth of the defect in an Eddy current signal. Applied Sciences 7, 1-12.

[16] Ihn JB \& Chang FK (2008), Pitch-catch active sensing methods in structural health monitoring for aircraft structures. Structural Health Monitoring 7, 5-19.

[17] Yu L \& Giurgiutiu V (2007), In-situ optimized PWAS phased arrays for Lamb wave structural health monitoring. Journal of Mechanics of Materials and Structures 2, 459-487.

[18] Zhu R, Huang GL \& Yuan FG (2013), Fast damage imaging using the time-reversal technique in the frequency-wavenumber domain Smart Materials and Structures 22, 1-12.

[19] Qiu L, Liu M, Qing X \& Yuan S (2013), a quantitative multidamage monitoring method for large-scale complex composite. Structural Health Monitoring 12, 183-196.

[20] Qiu L, Yuan S, Chang FK, Bao Q \& Mei H (2014), On-line updating Gaussian mixture model for aircraft wing spar damage evaluation under time-varying boundary condition. Smart Materials and Structures $23,1-16$

[21] Liu Y \& Chattopadhyay A (2013), Low-velocity impact damage monitoring of a sandwich composite wing. Journal of Intelligent Material Systems and Structures 24, 2074-2083.

[22] Liu Y, Fard MY, Chattopadhyay a \& Doyle D (2012), Damage assessment of CFRP composites using a time-frequency approach. Journal of Intelligent Material Systems and Structures 23, 397-413.

[23] Bro R \& Smilde AK (2014), Principal component analysis. Analytical Methods 6, 2812-2831

[24] Anaya M, Tibaduiza DA \& Pozo F (2015), A bioinspired methodology based on an artificial immune system for damage detection in structural health monitoring. Shock and Vibration 2015, 1-15.

[25] Burgos DT (2012), Design and validation of a structural health monitoring system for aeronautical structures. $\mathrm{PhD}$ thesis, Barcelona: Technical University of Catalonia.

[26] Jeong DH, Ziemkiewicz C, Fisher B, Ribarsky W \& Chang R (2009), iPCA: An interactive system for PCA-based visual analytics. Computer Graphics Forum, 28, 767-774. 